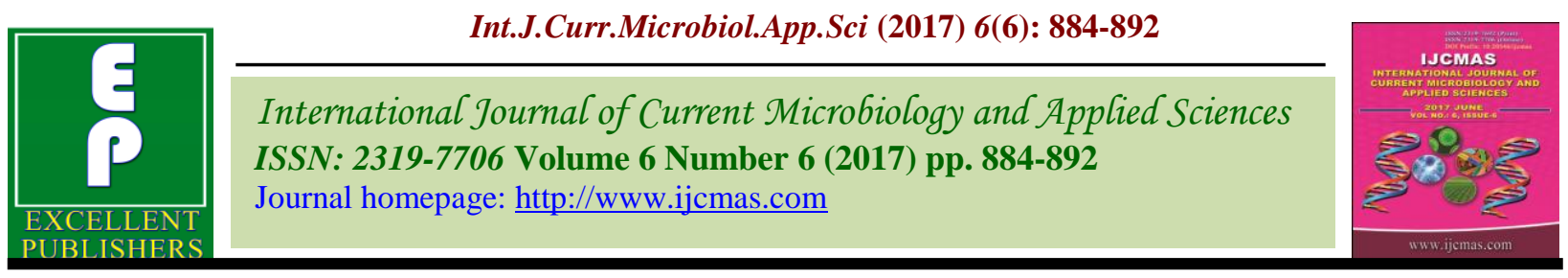

Original Research Article

https://doi.org/10.20546/ijcmas.2017.606.104

\title{
Prevalence of Candida Species and its Antifungal Susceptibility Isolated from Blood Culture at Tertiary Care Hospital, Ahmedabad, India
}

\author{
Vicky Gandhi ${ }^{*}$ and Mehul Patel ${ }^{2}$ \\ Department of Microbiology, GMERS Medical College, Valsad, India \\ *Corresponding author
}

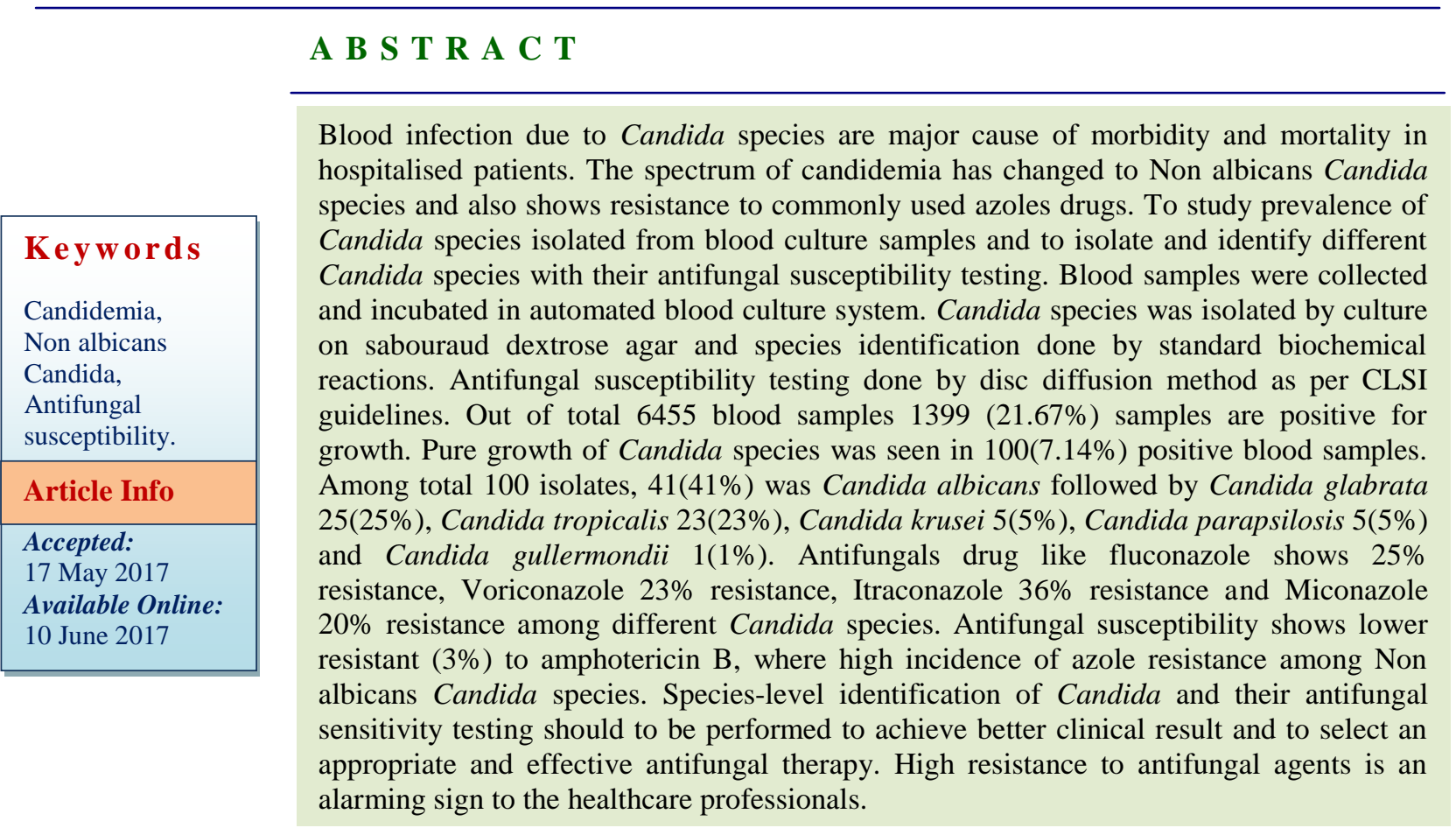

\section{Introduction}

Candida is the yeast like fungi which normally exist within mouth, throat, intestine, genital and urinary tract of human being (Chander et al., 2009). Candidemia is defined as at least 1 blood culture bottle positive for Candida species and other sign of blood stream infection. Episodes were considered separate if they occur 1 month apart or were caused by different species (Chen et al., 2003; Sandven et al., 2006). Candidemia is a life threatening fungal infection associated with mortality rate of $38 \%$ and prolongs hospital stay by as much as 30 days (Wey et al., 1998). Candida species infection are among the four most common causes for hospital acquired infection, catheter associated UTI and blood stream infection (Zaoutis et al., 2005). Candidemia is a manifestation of invasive candidiasis that could have originated in a variety of organs, whereas for others, candidemia originated from an infected indwelling catheter (Frikdin, 2005). The spectrum of Candidemia has changed 
with the emergence of non albicans Candida (NAC) species, a strain with threat of increasing mortality and antifungal drug resistance (Horvath et al., 2003).

In all cases, Candidemia requires treatment with an antifungal drug (Pappas et al., 2009). Several studies noted the high mortality rates associated with candidemia and have shown that mortality is highest in those patients who were not treated with an antifungal drug (Fraser et al., 1992; Nguyen et al., 1995). Early and prompt diagnosis, proper treatment for microbiologist and clinician worldwide added to this is emerging drug resistance to antifungal to the Candida species.

\section{Materials and Methods}

This study was conducted in microbiology department at tertiary care hospital, Ahmedabad during July 2012 to May 2013 over ${ }^{11}$ month's duration. Blood sample was collected in automated blood culture bottle under total aseptic precautions. Then blood culture bottle was put in automated microbial detection system based on the colorimetric detection of $\mathrm{CO}_{2}$ produced by microorganisms. After signalling positive for blood culture bottle, samples were inoculated on routine culture media and further tests were performed.

Primary identification done by direct smear examination blood samples by wet mount and gram stain. Sample was inoculated on Sabouraud dextrose agar (SDA) screw cap bottle and incubated at $37^{\circ} \mathrm{C}$ and $25^{\circ} \mathrm{C}$ for 48 72 hours. After growth, species identification done by Germ tube test, corn meal agar test, chrom agar inoculation, sugar assimilation test, sabouraud dextrose broth, urease test (Odds, 1998; Forbes et al., 2007; Hospenthal et al., 2006). Antifungal susceptibility testing done by disc diffusion method as described in CLSI document M-44-A(2) (Clinical Laboratory Standard institute Guidelines,
2009). Muller Hinton agar plates supplemented with $2 \%$ glucose and $0.5 \mu \mathrm{g} / \mathrm{ml}$ methylene blue was used. Antifungal drugs like Amphotericin B (100units/disc), Fluconazole (10mcg/disc), Itraconazole (30 mcg/disc), Miconazole (30 mcg/disc), Voriconazole (1mcg/disc) were used for antifungal susceptibility.

\section{Results and Discussion}

During this study period total 6455 blood culture samples were processed in automated blood culture machine by colorimetric method. Out of that 1399 (21.67\%) blood samples were signalling positive and processed for culture for identify organism. Out of 1399 signalling positive samples, 100 samples were identified as Candida species growth. A total of 100 samples were positive for Candida species out of total 6455 blood samples. So prevalence of Candida species was $1.54 \%(100 / 6455)$ in our study (Figure 1).

Out of the 100 Candida isolates, 41(41\%) were Candida albicans, followed by Candida glabrata 24(25\%), Candida tropicalis 23(23\%), Candida krusei 5(5\%), Candida parapsilosis $5(5 \%)$ and Candida gullermondii 1(1\%) (Figure 2).

In this study, Candida infection was more common $(73 \%)$ in $0-10$ years of age group, followed by $13 \%$ in $11-40$ years and $14 \%$ in 41-80 years of age group (Figure 3). Candida infection was more common in male $67 \%$ as compare to female $33 \%$ (Figure 4). Antifungal susceptibility pattern shows that Non albicans Candida species like Candida tropicalis, Candida glabrata and Candida parapsilosis tends to high resistant to azoles. Candida krusei is innately resistant to fluconazole. Amphotericin B was sensitive in $100 \%$ in Candida albicans, Candida parapsilosis and Candida krusei followed by $95.65 \%$ in Candida tropicalis and $92 \%$ in 
Candida glabrata (Table 1). The prevalence rate of Candida species in blood stream infection increase in last three decades, in last few years, various factors like AIDS epidemic, increases in the number of immunosuppressive therapy recipients and use of long term antibiotics therapy have altered the epidemiology of invasive mycoses, particularly in candidemia. More recently, Non albicans Candida species has been recovered with increasing frequency with more resistance to antifungal drugs.

In our study, the overall prevalence rate of isolation of Candida species from blood culture was $1.54 \%$ and 4 th most common causes for blood stream infection. Several studies done in India shows prevalence rate of Candidemia varies from $0.65 \%$ to $6.9 \%$ (Giri et al., 2013; Verma et al., 2003; Sanhi et al., 2005; Deorukhkhar et al., 2012) (Table 2).

The numbers of different Candida species isolated from blood stream infection has been increasing during the last few years in different parts of world. More than 17 species of Candida species have been implicated in human infections till date and list of reported species continue to grow. In our study, the incidence of blood stream infection caused by Non albicans Candida species was higher than Candida albicans (Table 3).

Table.1 Antifungal susceptibility pattern of different Candida species

\begin{tabular}{|c|c|c|c|c|c|}
\hline Candida Species & 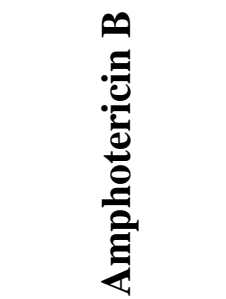 & 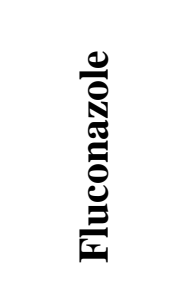 & 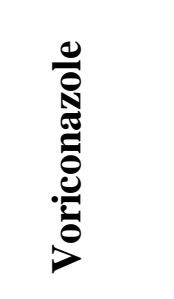 & 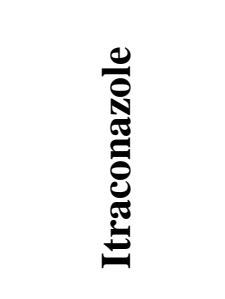 & 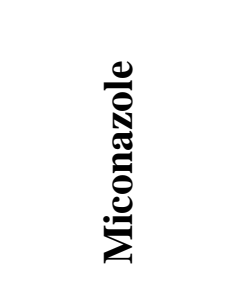 \\
\hline C. albicans (41) & $\begin{array}{c}41 \\
(100 \%)\end{array}$ & $\begin{array}{c}36 \\
(87.80 \%)\end{array}$ & $\begin{array}{c}35 \\
(85.36 \%)\end{array}$ & $29(70.73 \%)$ & $\begin{array}{c}32 \\
(78.04)\end{array}$ \\
\hline C. glabrata (25) & $23(92 \%)$ & $16(64 \%)$ & $18(72 \%)$ & $12(52.17 \%)$ & $21(84 \%)$ \\
\hline C. tropicalis (23) & $22(95.65 \%)$ & $\begin{array}{c}18 \\
(78.26 \%)\end{array}$ & $\begin{array}{c}15 \\
(65.21 \%)\end{array}$ & $15(65.21 \%)$ & $21(91.30 \%)$ \\
\hline C. parapsilosis (5) & $5(100 \%)$ & $4(80 \%)$ & $4(80 \%)$ & $4(80 \%)$ & $3(60 \%)$ \\
\hline C. krusei (5) & $5(100 \%)$ & $0(0 \%)$ & $4(80 \%)$ & $3(60 \%)$ & $2(40 \%)$ \\
\hline C. gullermondii (1) & $1(100 \%)$ & $1(100 \%)$ & $1(100 \%)$ & $1(100 \%)$ & $1(100 \%)$ \\
\hline
\end{tabular}


Table.2 A comparative study of prevalence of Candida species isolated from blood culture

\begin{tabular}{|c|c|}
\hline Study & $\begin{array}{c}\text { Prevalence of Candida species isolated } \\
\text { from blood culture }\end{array}$ \\
\hline Present Study & $\mathbf{1 . 5 4 \%}$ \\
\hline $\begin{array}{c}\text { S.Giri } \text { et al., (2013) Christian Medical College, } \\
\text { Vellore, Tamil Nadu }\end{array}$ & $0.65 \%$ \\
\hline $\begin{array}{c}\text { Verma } \text { et al., (2003) Sanjay Gandhi Post Graduate } \\
\text { Institute for Medical Sciences, Lucknow }\end{array}$ & $1.61 \%$ \\
\hline $\begin{array}{c}\text { Oberoi } \text { et al., (1988) Sir Ganga Ram Hospital, New } \\
\text { Delhi }\end{array}$ & $1.74 \%$ \\
\hline $\begin{array}{c}\text { Sahni } \text { et al., (2005) Maulana Azad Medical College, } \\
\text { New Delhi }\end{array}$ & $6.9 \%$ \\
\hline $\begin{array}{c}\text { Sachin Deorukhkhar } \text { et al., (2012) Rural Medical } \\
\text { College, Loni, Maharashtra }\end{array}$ & $3.9 \%$ \\
\hline $\begin{array}{c}\text { Xess } \text { et al., (2007) All India Institute of Medical } \\
\text { Science (AIIMS), New Delhi }\end{array}$ & $6.0 \%$ \\
\hline
\end{tabular}

Table.3 A comparative study of prevalence of different Candida species isolated from blood culture

\begin{tabular}{|c|c|c|c|c|c|c|}
\hline Species & 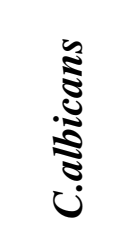 & ن. & 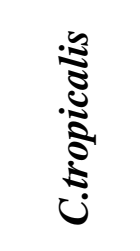 & 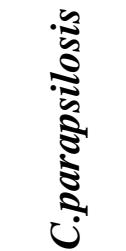 & $\frac{\tilde{v}}{\tilde{v}}$ & $\stackrel{\grave{d}}{\overline{0}}$ \\
\hline Present Study & $41 \%$ & $25 \%$ & $23 \%$ & $5 \%$ & $5 \%$ & $1 \%$ \\
\hline $\begin{array}{l}\text { Frank C. Odds et al., } \\
\text { (2007) Scotland UK }\end{array}$ & $52 \%$ & $22 \%$ & $2.0 \%$ & $11.7 \%$ & $1.0 \%$ & $11.3 \%$ \\
\hline $\begin{array}{l}\text { Peter g Pappas et al., } \\
\text { (2009) University of } \\
\text { Alabama USA }\end{array}$ & $46 \%$ & $20 \%$ & $12 \%$ & $14 \%$ & $2 \%$ & $6 \%$ \\
\hline $\begin{array}{c}\text { David L. Horn et al., } \\
\text { (2019) Philaedelphia, } \\
\text { Pennsylvania }\end{array}$ & $45.6 \%$ & $26.0 \%$ & $8.1 \%$ & $15.7 \%$ & $2.5 \%$ & $2.1 \%$ \\
\hline $\begin{array}{l}\text { Lena Rose (2013) } \\
\text { Asmundsdottir et al., } \\
\text { Iceland }\end{array}$ & $56 \%$ & $16 \%$ & $13 \%$ & $5 \%$ & $4 \%$ & $6 \%$ \\
\hline $\begin{array}{l}\text { Sachin Deorikhkar } \\
\text { (2012) Maharastra }\end{array}$ & $40.2 \%$ & $13.9 \%$ & $26.8 \%$ & $2.5 \%$ & $10 \%$ & $6.6 \%$ \\
\hline
\end{tabular}


Table.4 A comparative study of antifungal resistance in all Candida species isolated from blood culture

\begin{tabular}{|c|c|}
\hline Study & $\begin{array}{c}\text { Percentage resistance to antifungal drugs in all } \\
\text { Candida } \text { spp. isolated from blood culture }\end{array}$ \\
\hline Present Study & Fluconazole (25\%) \\
Itraconazole (36\%) \\
Voriconazole (23\%) \\
Amphotericin B (3\%)
\end{tabular}

Fig.1 Prevalence of various organisms isolated from blood culture

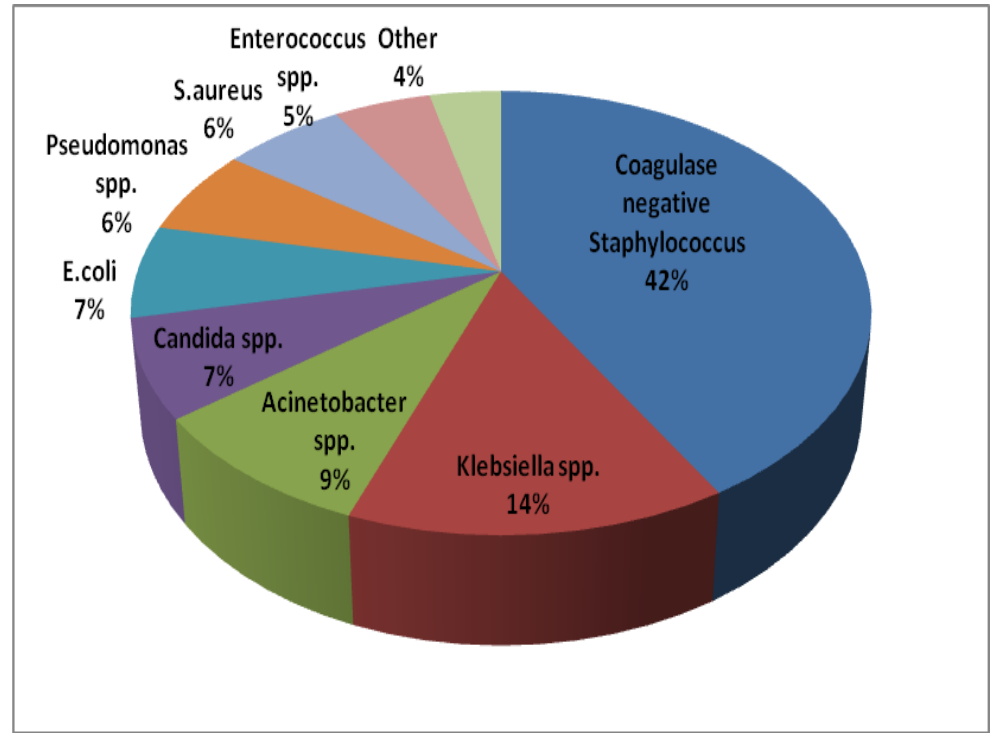


Fig.2 Different Candida species isolated from blood culture

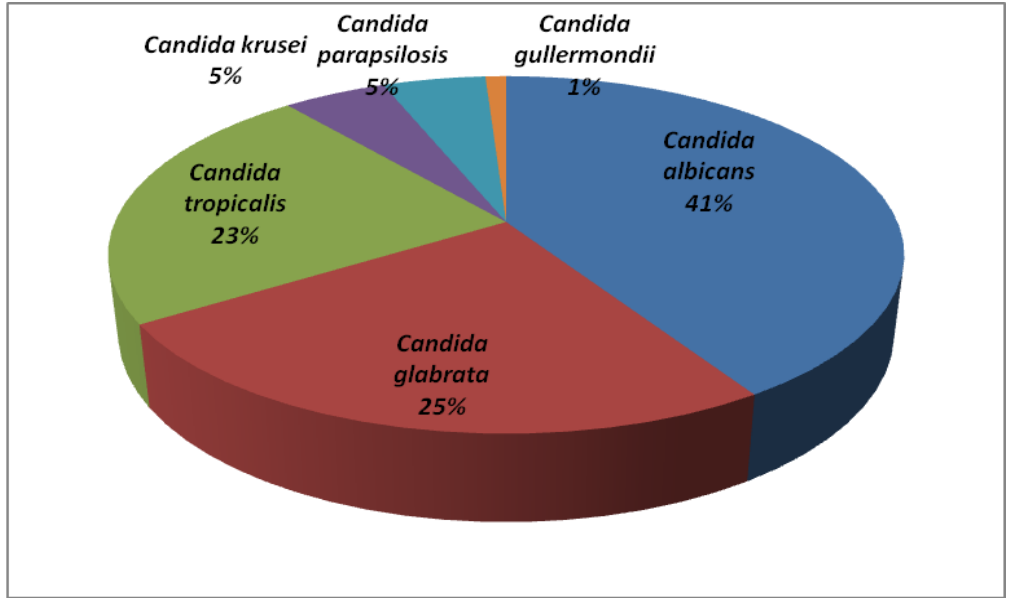

Fig.3 Age distribution of patients from which Candida species isolated

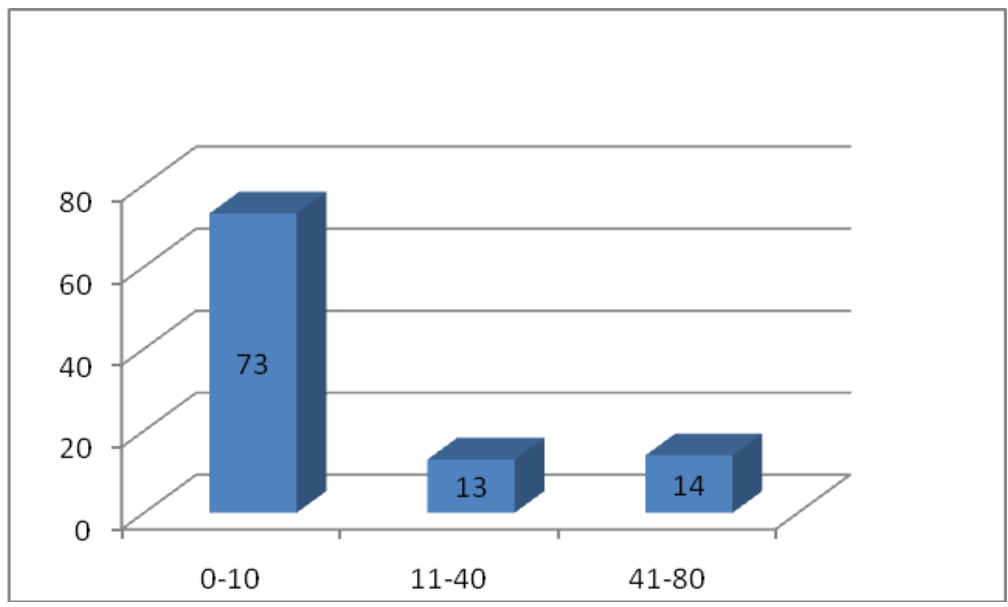

Fig.4 Sex distribution of patients from which Candida species isolated

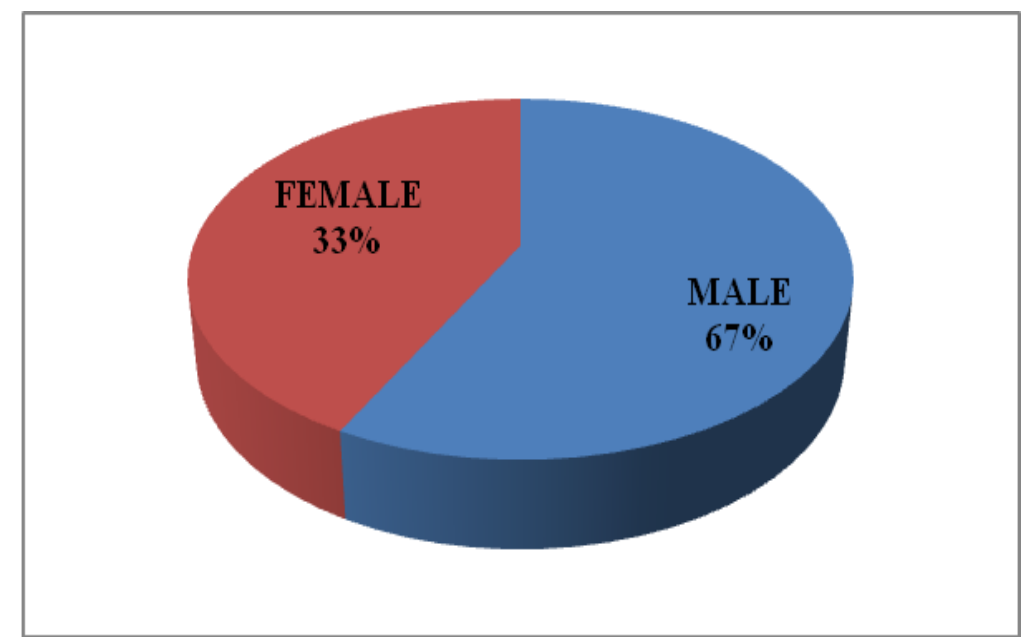


Neonates and infants have historically been populations with some of the highest rates of Candidemia (Shetty et al., 2005). In our study $72 \%$ of Candidemia were seen in neonates and infants. Candidemia is a significant cause of mortality and morbidity in neonates admitted in neonatal Intensive Care Unit. Candida species are the most common fungal pathogen isolated from blood culture of neonates. A numbers of risk factors like low birth weight baby, prematurity, prolonged antibiotics therapy and artificial ventilation are associated with Candidemia (Sardana et al., 2012; Rani et al., 2002). In our study all Candida isolates shows $25 \%$ resistance to Fluconazole, 23\% resistance to Voriconazole, $20 \%$ resistance to Miconazole, $36 \%$ resistance to itraconazole and only $3 \%$ resistance to amphotericin B. In India, there is lack of multicentric studies regarding antifungal susceptibility pattern. Goel et al., (2009) and Cooper et al., (2005) reported less incidence of resistance to fluconazole. On the other hand, Kumar et al., (2005), Kothari et al., (2009), and Gupta et al., (2001) reported high incidence of resistance to fluconazole (Table 4).

Although fluconazole still remains a safe and effective choice for the treatment of candidemia, an increase trend of fluconazole resistance in Candida isolates from blood has been reported mainly due to the changing spectrum of Candida species causing candidemia from $C$. albicans to Non albicans Candida species especially $C$. glabrata and C. krusei. In our study the highest rate of resistance to fluconazole was for $C$. glabrata (36\%) and for C. tropicalis $(22 \%)$ which was consistent with other studies in which the greatest resistance to fluconazole also showed C. glabrata $(36 \%)$.

The resistance to fluconazole is of great concern because it is the most common azole used for treatment of disseminated candidiasis including candidemia. It is available in both intravenous and oral formulation with high bioavailability and is more cost effective than other antifungal agents. Although Amphotericin B is effective against most strains of Candida species, it is not the first drug of choice for the treatment of candidemia because of nephrotoxicity associated with it. Many potential mechanisms of azole resistance have been proposed. Alteration of drug efflux, reduced intracellular accumulation of fluconazole due to change CDR genes and increased expression of ATP- binding cassette transporter gene are some of the mechanism for azole resistance in Candida species (Loffler et al., 2003; Alberstone et al., 1996).

In conclusion, our study shows Candida as among most common causes for blood stream infection. A significant epidemiological shift to higher isolation of Non albicans Candida species was noted because of high usage of fluconazole, patient's specific risk factors and also newer available diagnostic method. Hence it is essentials that early and accurate diagnosis is made of infecting species of Candida and its antifungal susceptibility testing be carried out routinely in laboratory.

\section{References}

Alberstone, G.D., Niimi, M., Cannon, R.D., et al. 1996. Multiple Efflux Mechanism are involved in Candida albicans fluconazole resistance. Antimicrob. Agent Chemother., 40: 2835-41.

Capoor, M.R., Nair, D., et al. 2005. Emergence of non albicans Candida and antifungal resistance in tertiary care hospital. Jpn. J. Infect. Dis., 58: 344348.

Chander, Jagdish. 2009. Textbook of Medical Mycology. 3rd edition, Mehta publisher; Page 266-283. 
Chen, S., Slavin, M., et al. 2003. Active surveillance of candidemia, Australia. Emerg. Inf. Dis., 9: 985-90.

Clinical Laboratory Standard institute. 2009. Guidelines Performance Standard for Antifungal Susceptibility by Disc Diffusion Method Supplement M-44-A.

Deorukhkhar, S.C., Saini, S. 2012. Species distribution and antifungal susceptibility profile of Candida species isolated from blood stream infections. J. Evol. Med. Dent. Sci., Issue 3 p 241-249.

Forbes, A., Betty, Sahn, F., Daniel. 2007. Bailey and Scott's Diagnostic Microbiology. 12th Edition. Eslevier Publisher, Pp. 696-709.

Fraser, V.J., Jones, M., et al. 1992. Candidemia in tertiary care hospital, epidemiology, risk factors, predictors of mortality. Clin. Infect. Dis., 15: 414.

Frikdin, S.K. 2005. The changing face of fungal infection in health care setting. Clin. Infect. Dis., 41: 1455.

Giri, S., Aj Kindo et al. 2013. Candidemia in Intensive Care Units Patients: A one year study from tertiary care hospital, South India. J. Postgraduate Med., 59(3): 190-195.

Goel, N., Ranjan, P.K., Agrawal, R., et al. 2009. Emergence of Non albicans Candida in Neonatal septicaemia and antifungal susceptibility: $J . \quad L a b$. Physician, 1: 53-55.

Gupta, N., Mittal, N., et al. 2001. Candidemia in Neonatal Intensive Care Unit. Ind. J. Pathol. Micro., 44: 45-8.

Horn, D.L., Neofytos, D., Anaisse, E.J., Fishman, J.A., et al. Epidemiology and Outcomes of Candidemia in 2019 Patients: Data from the prospective Antifungal Therapy Alliance Registry. CID, 48 (15June) 1695-1703.

Horvath, L.L., Hospenthal, D.R., Murray, C.K., Dooley, D.P. 2003. Direct isolation of Candida species from blood cultures on the chromogenic medium
CHROMAgar Candida. J. Clin. Microbiol., 41: 2629-2632.

Hospenthal, R., Duane, et al. 2006. Presumptive identification of Candida species other than $C$. albicans, $C$. tropicalis, C. krusei with chromogenic media CHROM agar Candida. Annals Clin. Microbiol. Antimicrobials, 5: 1-5.

Kothari, A., Sagar, V. 2009. Epidemiology of Candida blood stream infection in tertiary care hospital in India. Indian $J$. Med. Microbiol., 27: 171-172.

Kumar, C.P., Sundarajan, T., Menon, T., et al. 2005. Candidiosis in chidren with Onco haematological studies in Chennai, South India. Jpg. J. Infect. Dis., 58: 218-221.

Lena Rose, A., Helga, E., Magnus, G., et al. 2013. Nationwide study of candidemia, Antifungal use, and antifungal drug resistance in Iceland, 2000-2011. J. Clin. Microbiol., 51(3): 841-8.

Loffler, J., Stevenes, D.A. 2003. Antifungal Drug Resistence. Clin. Infect. Dis., 36 Suppl 1; S31-41.

Nguyen, M.H., Peacock, J.E., et al. 1995. Therapeutic approach in patients with candidemia. Arch. Intern. Med., 155: 2429.

Oberoi, J.K., Wattal, C., Goel, N., et al. 2012. Non albicans Candida species in blood stream infections in tertiary care hospital at New Delhi, India. Indian J. Med. Res., 136, Pp. 997-1003.

Odds, F.C. 1988. Isolation and other laboratory aspect of Candida, in Candidemia and candidiosis. A review and bibliography. 3rd edition. London, Toronto, Sydney, Tokyo: Briallierey tindall, Pp. 60-67.

Odds, F.C., Hanson, M.F., Davidson, A.D., et al. 2007. 1 year prospective survey of Candida bloodstream infection in Scotland. J. Med. Microbiol., 56: 10661075. 
Pappas, P.G., Kauffman, C.A., et al. 2009. Clinical practice guidelines for management of Candidiasis updated by the infectious disease society of America, Clin. Infect. Dis., 48: 503.

Pappas, P.G., Rex, J.H., Lee, J., et al. 2003. A Prospective Observational Study on Candidemia: Epidemiology, Therapy and Influences on Mortality in Hospitalised Adult and Paediatric Patients. Clin. Infect. Dis., 37: 634-43.

Rani, R., Mohapatra, N.P., Mehta, G., et al. 2002. Changing trend of Candida species in neonatal septicaemia in tertiary North Indian hospital. Ind. $J$. Med. Microbiol., 20: 42-4.

Sandven, P., Bevanger, et al. 2006. Candidemia in Norway (1991 to 2003); result from a nationwide study, J. Clin. Microbiol., 44: 1977-81.

Sanhi, V., Agraval, S.K., Singh, N.P., et al. 2005. Candidemia- an under recognised nosocomial infection in Indian hospitals. J. Associa. Physician India, 53: 607-611.

Sardana, V., Pandey, A., Madan, M., et al., Neonatal Candidemia: A changing trend. Indian J. Pathol. Microbiol., 55(1): 132-133.

Shetty, S.S., Harrison, L.H., et al. 2005. Determining risk factors for candidemia among new born Infants from population based surveillance. Baltimore, Maryland, 1998-2000. Paediatrics Infect. Dis., 24(7): 601-604.

Verma, A.K., Prasad, K.N., Singh, M., et al. 2003. Candidemia in patients from Tertiary Care Hospital from North India. Indian J. Med. Res., 117: 122-8.

Wey, S.B., Mori, M., Pfaller, M.A., Woolson, R.F., Wenzel, R.P. 1998. Hospital acquired candidemia: The attributable mortality and excess length of stay. Arch. Intern. Med., 148: 2642-2645.

Xess, I., Jain, N., Hasan, F., et al. 2007. Epidemiology of Candida in tertiary care hospital of North India; 5 year study. Infect., 35: 256-259.

Zaoutis, T.E., Argon, J., Chu, J., Berlin, J.A., Walsh, T.J., Feudtner, C. 2005. The epidemiology and attributable outcomes of candidemia in adults and children hospitalized in the United States: a propensity analysis. Clin. Infect. Dis., 41: 1232-1239.

\section{How to cite this article:}

Vicky Gandhi and Mehul Patel. 2017. Prevalence of Candida Species and its Antifungal Susceptibility Isolated From Blood Culture At Tertiary Care Hospital, Ahmedabad. Int.J.Curr.Microbiol.App.Sci. 6(6): 884-892. doi: https://doi.org/10.20546/ijcmas.2017.606.104 